\title{
Three 2 D copper(II)/cadmium(II) coordination polymers based on semi-rigid/flexible bis-pyridyl-bis-amide ligands and 5-aminoisophthalate: Syntheses, structures and properties
}

\author{
HONGYAN LIN ${ }^{\mathrm{a}}$, HUIZHE LU ${ }^{\mathrm{b}}$, MAO LE ${ }^{\mathrm{a}}, \mathrm{JIAN}$ LUAN $^{\mathrm{a}}$, XIULI WANG ${ }^{\mathrm{a}, *}$ and \\ GUOCHENG LIU \\ a Department of Chemistry, Bohai University, Jinzhou 121000, P. R. China \\ ${ }^{b}$ Department of Applied Chemistry, China Agricultural University, Beijing, 100193, P. R. China \\ e-mail: wangxiuli@bhu.edu.cn
}

MS received 22 December 2014; revised 7 April 2015; accepted 8 April 2015

\begin{abstract}
Three new transition metal coordination polymers [Cu(3-bpcb $\left.)_{0.5}(5-\mathrm{AIP})\right] \cdot 2 \mathrm{H}_{2} \mathrm{O}(\mathbf{1}),[\mathrm{Cd}(3-\mathrm{bpc}$ b) $\left.0.5(5-\mathrm{AIP})\left(\mathrm{H}_{2} \mathrm{O}\right)\right] \cdot \mathrm{H}_{2} \mathrm{O}(2)$ and $\left[\mathrm{Cd}(3-\text { bpsa })_{0.5}(5-\mathrm{AIP})\left(\mathrm{H}_{2} \mathrm{O}\right)\right] \cdot 2 \mathrm{H}_{2} \mathrm{O}(3)$ have been hydrothermally synthesized by self-assembly of 5-aminoisophthalic acid (5- $\left.\mathrm{H}_{2} \mathrm{AIP}\right)$, semi-rigid or flexible bis-pyridyl-bis-amide ligands [3$\mathrm{bpcb}=\mathrm{N} \mathrm{N}^{\prime}$-bis(3-pyridinecarboxamide)-1,4-benzene, 3-bpsa = N,N'-bis(3-pyridyl)succinamide], and copper chloride or cadmium nitrate. X-ray diffraction analysis reveals that compounds $\mathbf{1}$ and $\mathbf{2}$ possess similar $2 \mathrm{D}$ double-layered structures with $(3,4)$-connected $\left(6^{3}\right)\left(6^{5} \cdot 8\right)$ topology, while compound $\mathbf{3}$ displays a 2 D layer with $\left\{6^{2} .10\right\}\{6\}$ topology. The adjacent layers of $\mathbf{1}-\mathbf{3}$ are finally extended into $3 \mathrm{D}$ supramolecular frameworks by hydrogen bonding interactions. The bis-pyridyl-bis-amide ligands with different flexibilities play an important role in the construction of final topological structures for the title compounds. Further, the electrochemical behavior of the compound $\mathbf{1}$ and the fluorescent and photocatalytic properties of compounds 1-3 have been investigated.
\end{abstract}

Keywords. Bis-pyridyl-bis-amide ligand; coordination polymer; crystal structure; fluorescent property; photocatalytic property.

\section{Introduction}

Coordination polymers have attracted intensive attention during the past decades, not only for their diverse topological structures but also for their potential applications in catalysis, gas storage, luminescence and magnetism. ${ }^{1-3}$ Till now, a great number of these compounds with intriguing structures and desired properties have been successfully prepared by hydrothermal method. ${ }^{4-6}$ Although many factors can affect the ultimate structures of coordination compounds, the selection of suitable organic ligands plays a crucial role. ${ }^{7-9}$ Among the diverse organic ligands, the analogs of dipyridyl-based N-heterocyclic ligands has been widely utilized to bridge metal ions, and a large number of coordination compounds with intriguing architectures and interesting properties have been constructed with these organic ligands..$^{10-13}$

Recently, semi-rigid/flexible bis-pyridyl-bis-amide ligands as one of the dipyridyl-based ligands have proven to be excellent bridging ligands for building up metal-organic coordination frameworks and

\footnotetext{
*For correspondence
}

supramolecular networks, ${ }^{14-18}$ because it can satisfy the coordination requirements of metal ions by its backbone bending for appropriate twist angle and interact with each other by hydrogen bonds among the amide groups. For example, Cao's group and Chen's group have reported a series of transition metal $(\mathrm{Zn}, \mathrm{Cd}$, $\mathrm{Hg}$ ) coordination compounds based on the flexible bispyridyl-bis-amide ligands containing different $-\left(\mathrm{CH}_{2}\right)_{\mathrm{n}}$ ( $\mathrm{n}=0,4,10)$ backbones and aromatic polycarboxylates. ${ }^{19-21}$ Utilizing the mixed ligands of semi-rigid/ flexible bis-pyridyl-bis-amide ligands with various bridging backbones [benzene, cyclohexane, $-\left(\mathrm{CH}_{2}\right)_{n}$ - $(\mathrm{n}$ $=1-6,8)]$ and polycarboxylates, our group has prepared a series of $\mathrm{Co}$ (II)/Cu(II) coordination compounds showing remarkable photocatalytic activities for the degradation of organic dyes. ${ }^{22-25}$ However, so far, the related reports about $\mathrm{Cd}$ (II) coordination compounds based on semi-rigid/flexible bis-pyridyl-bis-amide ligands are limited, ${ }^{22,24}$ which prompted us to initiate this study.

In this paper, we select the $\mathrm{N}, \mathrm{N}^{\prime}$-bis(3-pyridinecarboxamide)-1,4-benzene (3-bpcb) and $\mathrm{N}, \mathrm{N}^{\prime}$-bis(3-pyri dyl)succinamide (3-bpsa) as neutral $\mathrm{N}$-heterocyclic ligands (scheme 1) and 5-aminoisophthalic acid (5- $\left.\mathrm{H}_{2} \mathrm{AIP}\right)$ as 

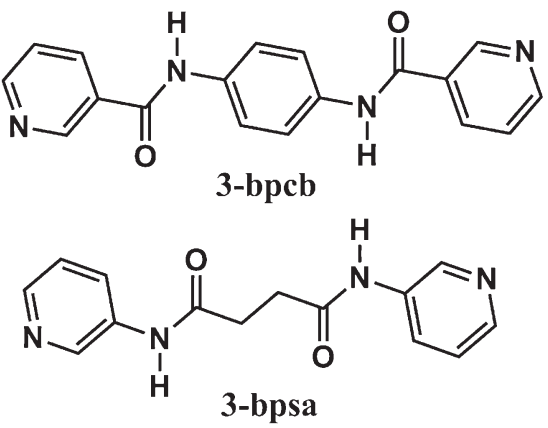

Scheme 1. The ligands 3-bpcb and 3-bpsa used in this work.

the auxiliary ligand, three new $3 \mathrm{D}$ supramolecular structural compounds based on $2 \mathrm{D}$ layered polymeric networks, $\left[\mathrm{Cu}(3-\mathrm{bpcb})_{0.5}(5-\mathrm{AIP})\right] \cdot 2 \mathrm{H}_{2} \mathrm{O}(\mathbf{1}),[\mathrm{Cd}(3-\mathrm{bp}$ $\left.\mathrm{cb})_{0.5}(5-\mathrm{AIP})\left(\mathrm{H}_{2} \mathrm{O}\right)\right] \cdot \mathrm{H}_{2} \mathrm{O}$ (2) and $\left[\mathrm{Cd}(3-\text { bpsa })_{0.5}(5-\mathrm{A}\right.$ IP) $\left.\left(\mathrm{H}_{2} \mathrm{O}\right)\right] \cdot 2 \mathrm{H}_{2} \mathrm{O}(3)$ have been successfully prepared under hydrothermal conditions. The influence of bispyridyl-bis-amide ligands with different flexibilities on the structures of coordination compounds has been discussed. Moreover, the thermal stability, electrochemical behavior of compound $\mathbf{1}$ bulk-modified carbon paste electrode (1-CPE), fluorescent and photocatalytic properties of the title compounds have been studied.

\section{Experimental}

\subsection{Materials and methods}

Ligands 3-bpcb and 3-bpsa were synthesized by the methods of the literature. ${ }^{26,27}$ Other chemical reagents were commercially obtained and used without further purification. FT-IR spectra (KBr pellets) were measured on a Varian FT-IR 640 spectrometer with $\mathrm{KBr}$ pellet in the $500-4000 \mathrm{~cm}^{-1}$ region. Thermogravimetric analyses (TGA) were carried out with a Pyris Diamond TGDTA instrument. The fluorescence spectra were taken on a HITACHI F-4500 Fluorescence Spectrophotometer. Electrochemical experiments were performed with a CHI 440 Electrochemical workstation. A conventional three-electrode cell was used at room temperature. The carbon paste electrode bulk-modified with compound 1 (1-CPE) was used as working electrode. ${ }^{14}$ An SCE and a platinum wire were used as reference and auxiliary electrodes, respectively.

\subsection{Preparation of the complexes}

2.2a Synthesis of $\left[\mathrm{Cu}(3-b p c b)_{0.5}(5-\mathrm{AIP})\right] \cdot 2 \mathrm{H}_{2} \mathrm{O}$ (1): A mixture of $\mathrm{CuCl}_{2} \cdot 2 \mathrm{H}_{2} \mathrm{O} \quad(0.034 \mathrm{~g}, 0.20 \mathrm{mmol})$, 5- $\mathrm{H}_{2}$ AIP $\quad(0.036 \mathrm{~g}, \quad 0.20 \mathrm{mmol}), \quad 3-\mathrm{bpcb} \quad(0.032 \mathrm{~g}$,
$0.10 \mathrm{mmol}), \mathrm{H}_{2} \mathrm{O}(12 \mathrm{~mL})$ and $\mathrm{NaOH}(0.014 \mathrm{~g}$, $0.35 \mathrm{mmol}$ ) was stirred for $20 \mathrm{~min}$, then transferred and sealed in a $25 \mathrm{~mL}$ Teflon reactor, which was heated at $120^{\circ} \mathrm{C}$ for 4 days leading to the formation of blue block crystals 1. Yield: $\sim 33 \%$ (based on $\mathrm{Cu}$ ). Anal. Calc. for $\mathrm{C}_{17} \mathrm{H}_{16} \mathrm{CuN}_{3} \mathrm{O}_{7}$ (437.88): $\mathrm{C} 46.63, \mathrm{H} 3.68, \mathrm{~N} 9.60$. Found: C 46.51, H 3.52, N 9.82\%. IR $\left(\mathrm{KBr}, \mathrm{cm}^{-1}\right)$ : $v=3560 \mathrm{~m}, 3478 \mathrm{~m}, 3415 \mathrm{~s}, 3231 \mathrm{w}, 2362 \mathrm{~m}, 1645 \mathrm{~m}$, $1613 \mathrm{~s}, 1550 \mathrm{~s}, 1511 \mathrm{~m}, 1480 \mathrm{w}, 1391 \mathrm{~s}, 1296 \mathrm{~m}, 1251$ w, 1176 w, 1081 w, 916 w, 834 m, 751 w, 618 s, 527 w.

2.2b Synthesis of $\left[\mathrm{Cd}(3-b p c b)_{0.5}(5-\mathrm{AIP})\left(\mathrm{H}_{2} \mathrm{O}\right)\right] \cdot \mathrm{H}_{2} \mathrm{O}$ (2): The synthesis method of $\mathbf{2}$ is similar to that for 1 except for $\mathrm{Cd}\left(\mathrm{NO}_{3}\right)_{2} \cdot 2 \mathrm{H}_{2} \mathrm{O}(0.063 \mathrm{~g}, 0.23 \mathrm{mmol})$ as the substitute of $\mathrm{CuCl}_{2} \cdot 2 \mathrm{H}_{2} \mathrm{O}(0.034 \mathrm{~g}, 0.20 \mathrm{mmol})$, and the different amount of $\mathrm{NaOH}(0.018 \mathrm{~g}, 0.45 \mathrm{mmol})$ was added to adjust $\mathrm{pH}$ value. Yield: $\sim 39 \%$ (based on Cd). Anal. Calc. for $\mathrm{C}_{17} \mathrm{H}_{16} \mathrm{CdN}_{3} \mathrm{O}_{7}$ (486.73): $\mathrm{C} 41.95$, H 3.31, N 8.63. Found: C 41.71, H 3.22, N 8.80\%. IR $\left(\mathrm{KBr}, \mathrm{cm}^{-1}\right): v=3490 \mathrm{~m}, 3392 \mathrm{~m}, 3210 \mathrm{~s}, 3042 \mathrm{w}$, $2364 \mathrm{~m}, 1619 \mathrm{~s}, 1561 \mathrm{~s}, 1480 \mathrm{w}, 1436 \mathrm{w}, 1366 \mathrm{~s}, 1265$ s, 1163 m, 1112 w, 1068 w, 1011 m, 929 w, 827 s, 745 s, 643 w, 592 w, 535 w.

$2.2 \mathrm{c}$ Synthesis of $\left[\mathrm{Cd}(3-\text { bpsa })_{0.5}(5-\mathrm{AIP})\left(\mathrm{H}_{2} \mathrm{O}\right)\right] \cdot 2 \mathrm{H}_{2} \mathrm{O}$ (3): The synthesis method of $\mathbf{3}$ is similar to that for $\mathbf{2}$ except for 3-bpsa $(0.027 \mathrm{~g}, 0.10 \mathrm{mmol})$ was used instead of 3-bpcb $(0.032 \mathrm{~g}, 0.10 \mathrm{mmol})$, and different amount of $\mathrm{NaOH}(0.016 \mathrm{~g}, 0.40 \mathrm{mmol})$ was added to adjust the $\mathrm{pH}$ value. Yield: $\sim 43 \%$ (based on $\mathrm{Cd}$ ). Anal. Calc. for $\mathrm{C}_{15} \mathrm{H}_{18} \mathrm{CdN}_{3} \mathrm{O}_{8}$ (480.72): C 37.48, $\mathrm{H}$ 3.77, $\mathrm{N}$ 8.74. Found: C 37.61, H 3.62, N 8.91\%. IR $\left(\mathrm{KBr}, \mathrm{cm}^{-1}\right)$ : $v=3420 \mathrm{w}, 3368 \mathrm{~s}, 3080 \mathrm{w}, 2928 \mathrm{~s}, 2865 \mathrm{w}, 1675 \mathrm{~s}$, 1470 s, $1420 \mathrm{w}, 1370 \mathrm{~s}, 1321 \mathrm{~s}, 1280 \mathrm{~s}, 1198 \mathrm{w}, 1127 \mathrm{~s}$, 1047 w, 1007 m, 809 w, 770 s, 716 w, 614 w, 530 w.

\section{$2.3 X$-ray crystallography}

Crystallographic data for the title compounds were collected using a Bruker Smart Apex II diffractometer $($ Mo-K $\alpha$ radiation, graphite monochromator, $\lambda=$ $0.71073 \AA$ for $\mathbf{1}$ and $\mathbf{3}, \lambda=0.71069 \AA$ for 2 ) by $\omega$ scan mode in the range of $1.50^{\circ} \leq \theta \leq 25.00^{\circ}$ for $1144^{\circ} \leq \theta \leq 25.00^{\circ}$ for 2 and $1.90^{\circ} \leq \theta \leq$ $24.99^{\circ}$ for 3 . Structure solution and refinement based on observed reflections gave the final $R_{1}\left(w R_{2}\right)=0.0398$ $(0.1241)$ for $\mathbf{1}, R_{1}\left(w R_{2}\right)=0.0284(0.0662)$ for 2 and $R_{1}\left(w R_{2}\right)=0.0475(0.1213)$ for $\mathbf{3}$. All of the structures were solved by direct methods and refined on $F^{2}$ by full-matrix least-squares methods using the SHELXS program of the SHELXTL package. ${ }^{28,29}$ Metal atoms in the compounds were located from the $E$-maps, and all 
non-hydrogen atoms were refined anisotropically. The hydrogen atoms of the organic ligands were placed in geometrically idealized positions and refined isotropically. The hydrogen atoms of lattice water and coordinated water molecules in compounds 1-3 were added by difference Fourier maps. But the hydrogen atoms of nitrogen atom (N1) from the 5-AIP ligand could not be found from the residual peaks and were directly included in the final molecular formula for compound $\mathbf{2}$. A summary of crystal data and structure refinements for the title compounds are provided in table 1 . The coordination modes of metal ions and organic ligands in compounds 1-3 are listed in table 2. The data of selective bond distances and angles are listed in table S1. The related hydrogen bonding geometries of $\mathbf{1}-\mathbf{3}$ are given in table $\mathrm{S} 2$.

\section{Results and Discussion}

\subsection{Synthesis}

Some factors may affect crystallization and structural formation of the coordination polymers in the hydrothermal reactions, such as initial reactants, reactant ratio, temperature and systematic $\mathrm{pH}$, etc. ${ }^{30,31}$ In order to investigate the influence of different factors on the assembly of coordination polymers, we tried to synthesize the title compounds by selecting copper(II)/cadmium ions, two semi-rigid/flexible bis-pyridyl-bis-amide ligands, as well as adjusting the reactants ratio and $\mathrm{pH}$. Although we have successfully prepared compounds $\mathbf{1}-\mathbf{3}$, the yields for the title compounds are low $(<50 \%$ in all case). There are amounts of byproducts during the hydrothermal synthesis, which may be the unreacted organic ligands or non-crystalline target/desired complexes. The experimental results indicate that syntheses of the compounds are affected not only by the stoichiometries of the reactants but also by the types of co-ligands in the reaction medium. ${ }^{32}$

The dicarboxylate ligands are extremely suitable to participate in the construction of coordination architectures with transitional metal ions, wherein the former can adopt various coordination geometries by utilizing their carboxyl groups in completely or partially deprotonated state. So, the introduction of bridging dicarboxylates is beneficial towards the formation of intricate coordination polymers. ${ }^{19,33}$ In addition, the differences of substituent groups have influence on the final architectures of the coordination polymers. In this work, the dicarboxylic acid $5-\mathrm{H}_{2}$ AIP with the electron-donating amino group is selected due to the following advantages: (i) serving as a naturally bent ligand, it possesses the dissymmetric unit with high rigidity, which tends to yield metal-organic compounds without interpenetrating structures, ${ }^{34}$ (ii) it is closely similar to the tripus-type 1,3,5-benzenetricarboxylic acid (1,3,5- $\left.\mathrm{H}_{3} \mathrm{BTC}\right)$ ligand, and its one amino group and two carboxyl groups may provide potential coordination sites leading to generation of high dimensional compounds. ${ }^{35}$ In compounds 1-3, 5-AIP anions

Table 1. Crystal data and structure refinement for compounds 1-3.

\begin{tabular}{|c|c|c|c|}
\hline Empirical formula & $\mathrm{C}_{17} \mathrm{H}_{16} \mathrm{CuN}_{3} \mathrm{O}_{7}$ & $\mathrm{C}_{17} \mathrm{H}_{16} \mathrm{CdN}_{3} \mathrm{O}_{7}$ & $\mathrm{C}_{15} \mathrm{H}_{18} \mathrm{CdN}_{3} \mathrm{O}_{8}$ \\
\hline $\begin{array}{l}\text { Formula weight } \\
\text { Crystal system }\end{array}$ & $\begin{array}{c}437.88 \\
\text { Monoclinic }\end{array}$ & $\begin{array}{c}486.73 \\
\text { Triclinic }\end{array}$ & $\begin{array}{c}480.72 \\
\text { Triclinic }\end{array}$ \\
\hline Space group & $\mathrm{P} 21 / \mathrm{c}$ & P -1 & P -1 \\
\hline$a, \AA$ & $15.1463(13)$ & $7.9088(8)$ & $8.540(3)$ \\
\hline$b, \AA$ & $7.6805(7)$ & $8.1050(8)$ & $10.039(3)$ \\
\hline$c, \AA$ & $15.6641(13)$ & $14.6760(15)$ & $11.214(4)$ \\
\hline$\alpha, \circ$ & 90 & $89.140(2)$ & $92.837(6)$ \\
\hline$\beta,{ }^{\circ}$ & $116.4100(10)$ & $75.2470(10)$ & $105.408(7)$ \\
\hline$\gamma, \circ$ & 90 & $80.092(2)$ & $102.628(6)$ \\
\hline$V, \AA^{3}$ & $1632.1(2)$ & $895.75(16)$ & $898.5(5)$ \\
\hline Z & 4 & 2 & 2 \\
\hline$D_{\text {calc }}, g \cdot \mathrm{cm}^{-3}$ & 1.782 & 1.805 & 1.777 \\
\hline$\mu, \mathrm{mm}^{-1}$ & 1.390 & 1.266 & 1.265 \\
\hline $\mathrm{F}(000)$ & 896 & 486 & 244 \\
\hline Total reflections & 8315 & 4628 & 5077 \\
\hline Unique reflections & 2872 & 3139 & 3158 \\
\hline$R_{\text {int }}$ & 0.0293 & 0.0160 & 0.0330 \\
\hline GOOF & 1.082 & 1.041 & 1.033 \\
\hline$R_{1}^{a}[I>2 \sigma(I)]$ & 0.0398 & 0.0284 & 0.0475 \\
\hline$w R_{2}^{b}$ (all data) & 0.1241 & 0.0662 & 0.1213 \\
\hline
\end{tabular}

${ }^{\mathrm{a}} R_{1}=\Sigma|| F_{\mathrm{o}}|-| F_{\mathrm{c}}|| / \Sigma\left|F_{\mathrm{o}}\right| ;{ }^{\mathrm{b}} w R_{2}=\Sigma\left[w\left(F_{\mathrm{o}}^{2}-F_{\mathrm{c}}^{2}\right)^{2}\right] / \Sigma\left[w\left(F_{\mathrm{o}}^{2}\right)^{2}\right]^{1 / 2}$ 
Table 2. The coordination numbers and modes of metal ions, 5- $\mathrm{H}_{2}$ AIP, 3-bpcb and 3-bpsa ligands in compounds 1-3.

Letal ions

adopted two different coordination modes (table 2), which bridge the metal ions to build $2 \mathrm{D}$ layers (for compounds 1-2) or $1 \mathrm{D}$ ribbon-like chain for compound 3 .

3.2 Description of crystal structures of $\left[\mathrm{Cu}(3-\mathrm{bpcb})_{0.5}\right.$ $(5-\mathrm{AIP})] \cdot 2 \mathrm{H}_{2} \mathrm{O}(\mathbf{1})$ and $\left[\mathrm{Cd}(3-b p c b)_{0.5}(5-\mathrm{AIP})\left(\mathrm{H}_{2} \mathrm{O}\right)\right]$. $\mathrm{H}_{2} \mathrm{O}(2)$

Single crystal X-ray diffraction analyses reveal that compounds 1-2 crystallize in the monoclinic space group P21/c and possess similar $2 \mathrm{D}$ double-layered structures, so we will discuss in detail the structure of compound $\mathbf{1}$ as an example. The asymmetric unit of compound 1 contains one crystallographically independent $\mathrm{Cu}$ (II) ion, a half of 3-bpcb ligand, one 5-AIP anion and two lattice water molecules. As shown in figure $1 \mathrm{a}$, the $\mathrm{Cu}$ (II) ion is penta-coordinated by one pyridyl nitrogen atom from a 3-bpcb ligand with $\mathrm{Cu} 1-$ N2 distance of 1.995(3) $\AA$, an amino nitrogen atom of a 5-AIP anion with Cu1-N1\#2 distance of 2.270(3) $\AA$ and three carboxyl oxygen atoms of two separated 5-AIP anions [the distances: $\mathrm{Cu} 1-\mathrm{O} 2 \# 1,1.910(3) \AA$; $\mathrm{Cu} 1-\mathrm{O} 3$, 2.075(2) $\AA$; Cu1-O4, 2.033(3) $\AA$ ], completing a distorted tetragonal pyramid geometry. The bond angles around the $\mathrm{Cu}(\mathrm{II})$ ion are $99.71(11)^{\circ}$ for $\mathrm{N} 2-\mathrm{Cu}-\mathrm{N} 1 \# 1$, $63.58(10)^{\circ}-93.19(10)^{\circ}$ for $\mathrm{O}-\mathrm{Cu}-\mathrm{O}$, and $89.88(11)^{\circ}-$ $153.54(12)^{\circ}$ for $\mathrm{O}-\mathrm{Cu}-\mathrm{N}$.

In compound 1, each 5-AIP anion adopts a monodentate-monodentate-chelating coordination mode (table 2): one carboxyl group coordinates to one $\mathrm{Cu}$ (II) ion with a monodentate mode, the other group coordinates to another $\mathrm{Cu}$ (II) ion exhibiting a chelating mode, and the amino group also coordinates to one $\mathrm{Cu}$ (II) ion showing a monodentate mode. The adjacent $\mathrm{Cu}$ (II) ions are bridged by the 5-AIP anions to form a $2 \mathrm{D}[\mathrm{Cu}(5-\mathrm{AIP})]_{\mathrm{n}}$ layer (figure $1 \mathrm{~b}$ ). Without considering the connection of 3-bpcb ligand, the 5-AIP anion serves as a $\mu_{3}$-bridging ligand and connects $\mathrm{Cu}$ (II) ions to build a $2 \mathrm{D}(6,3)$ hexagonal grid polymeric network (figure S1). Then two neighbouring layers are interlinked by 3 -bpcb ligands with a bidentate bridging mode (via ligation of pyridyl nitrogen atoms, table 2) to produce a honeycomb-like double-layer structure (figure 1c), in which the 3-bpcb ligand bridges two $\mathrm{Cu}$ (II) ions from two adjacent layers with the $\mathrm{Cu} \cdots \mathrm{Cu}$ non-bonding distance of $17.99 \AA$. The dihedral angle between two pyridyl rings of 3-bpcb ligand is $0^{\circ}$.

In the $2 \mathrm{D}$ network of 1 , each $\mathrm{Cu}$ (II) ion is surrounded by three 5-AIP anions and one 3-bpcb ligands, which can be regarded as a 4-connected node. 


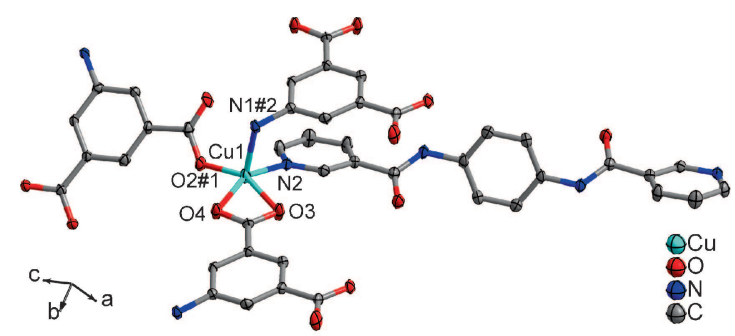

(a)

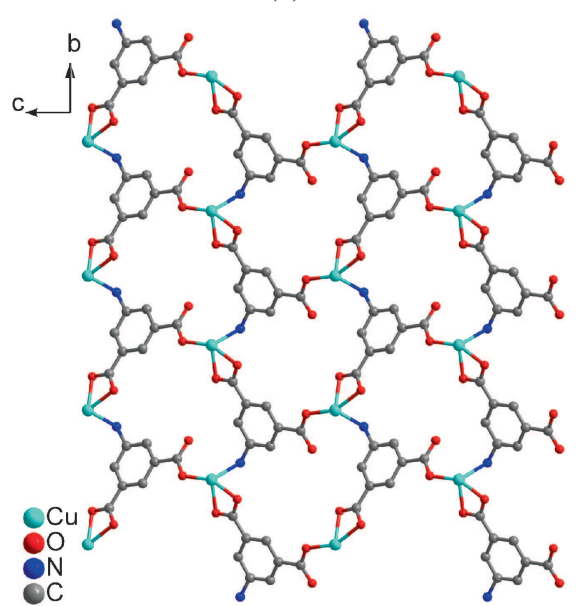

(b)

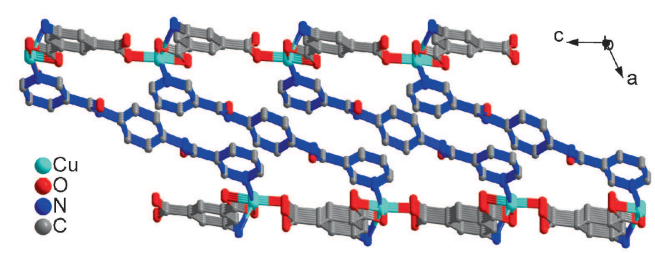

(c)

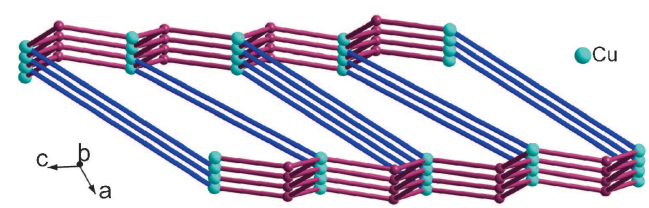

(d)

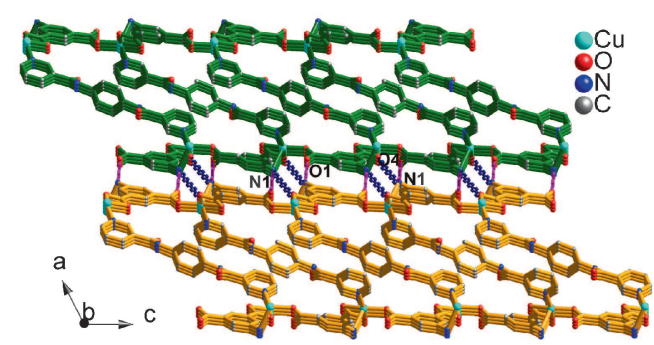

(e)

Figure 1. (a) The coordination environment for $\mathrm{Cu}(\mathrm{II})$ ion in compound 1 (at 50\% probability level); (b) The $2 \mathrm{D}[\mathrm{Cu}(5-$ AIP) $]_{n}$ layer formed by 5-AIP ligand in 1; (c) The 2 D double layer of 1 formed by [Cu(5-AIP) $]_{n}$ layer and 3-bpcb ligands; (d) The scheme of $2 \mathrm{D}$ double layer in 1; (e) The $3 \mathrm{D}$ supramolecular framework of compound $\mathbf{1}$ formed by hydrogen bonding interactions [hydrogen bond: blue dot line,

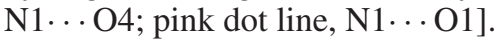

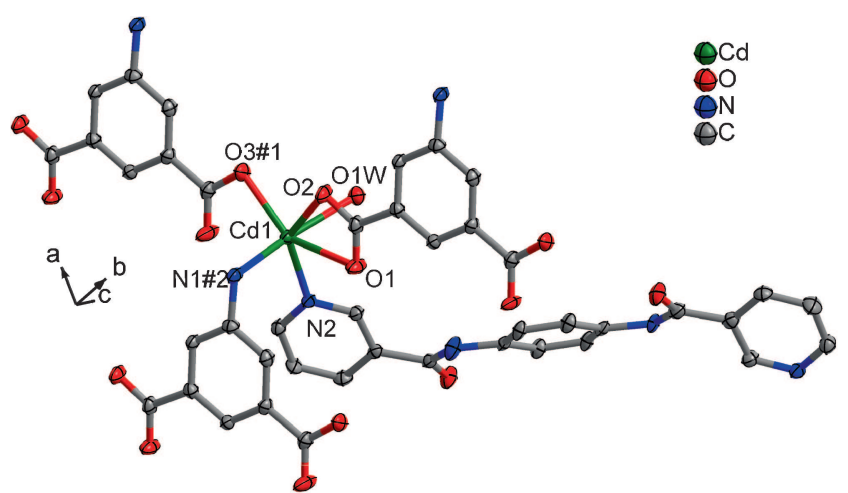

(a)

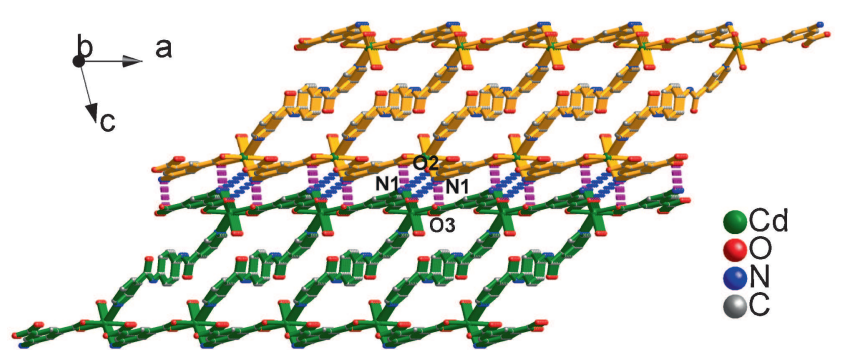

(b)

Figure 2. (a) The coordination environment for $\mathrm{Cd}(\mathrm{II})$ ion in compound 2 (at $50 \%$ probability level); (b) The $3 \mathrm{D}$ supramolecular framework of $\mathbf{1}$ formed by hydrogen bonding interactions [hydrogen bond: blue dot line, N1… O2; pink dot line, N1… 3 ].

Each 5-AIP anion bridges three $\mathrm{Cu}$ (II) ions, which is defined as a 3-connected node. Each 3-bpcb ligand with bidentate bridging mode is regarded as a simple linear linker. Thus, the $2 \mathrm{D}$ structure of $\mathbf{1}$ can be classified as a $(3,4)$-connected binodal topology, and its Schläfli symbol is $\left\{6^{3}\right\}\left\{6^{6}\right\}$ (figure 1d). The neighboring $2 \mathrm{D}$ double-layer networks are further extended into a 3 D supramolecular network by hydrogen bonding interactions between the nitrogen atom (N1) and oxygen atoms $(\mathrm{O} 1$ or $\mathrm{O} 4)$ of 5-AIP ligands [N1-H1A $\cdots \mathrm{O} 1=$ 3.163(4) $\AA, \mathrm{N} 1-\mathrm{H} 1 \mathrm{~B} \cdots \mathrm{O} 4=2.989(5) \AA]$ (figure 1e).

For compounds 1-2, based on the same mixedligands system of the semi-rigid 3-bpcb and 5-AIP, we obtained two similar 2 D polymeric networks. However, there are some intrinsic differences among them. In $\mathbf{2}$, the $\mathrm{Cd}$ (II) ion adopts a six-coordinated distorted octahedral geometry (figure $2 \mathrm{a}$ and table 2), which is significantly different from five-coordinated $\mathrm{Cu}$ (II) ion in 1. For $\mathrm{Cu}(\mathrm{II})$ and $\mathrm{Cd}(\mathrm{II})$ ions, the difference of the coordination modes may be due to their different atomic radius. In $\mathbf{2}$, the coordination mode of 5-AIP ligand is the same as that in $\mathbf{1}$, and the 3bpcb also adopts the similar bidentate bridging mode (table 2). But slight differences of conformations for 
ligand 3-bpcb can be observed. In compound 1, the 3-bpcb bridges two $\mathrm{Cu}$ (II) ions with the non-bonding Cu1 … Cu1 distances of $17.99 \AA$; while in 2, the 3-bpcb links two $\mathrm{Cd}(\mathrm{II})$ ions and the non-bonding $\mathrm{Cd} 1 \cdots \mathrm{Cd} 1$ distance is $15.58 \AA$. Due to the differences on coordination numbers of metal ions and coordination modes of organic ligand 3-bpcb in compounds $\mathbf{1}$ and $\mathbf{2}$, the final $3 \mathrm{D}$ supramolecular networks are slightly different (figure 2b).

In our previous studies, by utilizing the same 3-bpcb ligand, three $\mathrm{Cu}$ (II) compounds derived from three different polycarboxylates (1,2- $\mathrm{H}_{2} \mathrm{BDC}$ 1,2-benzenedicarboxylate; $\mathrm{H}_{2} \mathrm{SIP}$, 5-sulfoisophthalic acid; $\mathrm{H}_{4}$ btec, 1,2,4,5-benzene tetracarboxylic acid) have been obtained, ${ }^{36,37}\left[\mathrm{Cu}_{3}(3-\mathrm{bpcb})(1,2-\mathrm{BDC})_{2}\left(\mu_{2}-\mathrm{OH}\right)_{2}\right],\left[\mathrm{Cu}_{2}\right.$ (3-bpcb) $\left.)_{1.5}(\mathrm{SIP})\left(\mu_{3}-\mathrm{OH}\right)\right] \cdot \mathrm{H}_{2} \mathrm{O}$ and $\left[\mathrm{Cu}_{3}(3 \mathrm{bpcb})_{3}(\mathrm{btec})\right.$ 1.5 , which represent three different $3 \mathrm{D}$ coordination networks: a 4-nodal mixed (3,4,4,5)-connected 3D structure with the $(3 \cdot 4 \cdot 5)_{2}\left(3 \cdot 4^{2} \cdot 5 \cdot 8^{6}\right)_{2}\left(3^{2} \cdot 8 \cdot 9^{2} \cdot 10\right)\left(4^{2} \cdot 8^{2} \cdot 10^{2}\right)$ Schläfli symbol, a novel 3 -nodal $(5,6,6)$-connected $\left(3^{3} \cdot 4^{3} \cdot 5^{3} \cdot 6^{3} \cdot 7^{2} \cdot 8\right)\left(3^{3} \cdot 4^{3} \cdot 5^{3} \cdot 6\right)\left(3^{3} \cdot 4^{6} \cdot 5^{4} \cdot 6^{2}\right)$ topology and a unique trinodal 4-connected $\left(6^{4} \cdot 8^{2}\right)_{3}$ topology. In this study, we have obtained compound $\mathbf{1}$ with a 2 D layered structure by selecting the dicarboxylate 5AIP. The results reveal that different polycarboxylates play an important role in the formation of different coordination frameworks. Moreover, we have also prepared four $\mathrm{Co}$ (II) compounds based on the 3-bpcb ligand and four different aromatic dicarboxylates with various substituent groups (3-nitrophthalic acid, 5nitroisophthalic acid, 1,3-benzenedicarboxylate and $\left.5-\mathrm{H}_{2} \mathrm{AIP}\right),{ }^{15,38}$ showing three diverse $2 \mathrm{D}$ polymeric layers and one $1 \mathrm{D}$ chain-like structure, which indicates that the substituent groups of dicarboxylates play an important role in the assembly of metal-organic compounds. Although, several related $\mathrm{Co}$ (II) and $\mathrm{Cu}(\mathrm{II})$ compounds based on the 3-bpcb ligand have been obtained, the $\mathrm{Cd}(\mathrm{II})$ compound containing the 3-bpcb ligand has not been synthesized so far. Compound 2 represents the first $\mathrm{Cd}$ (II) compound derived from the semi-rigid bis-pyridyl-bis-amide ligand 3-bpcb.

\subsection{Description of crystal structures of $\left[\mathrm{Cd}(3-b p s a)_{0.5}(5-\mathrm{AIP})\left(\mathrm{H}_{2} \mathrm{O}\right)\right] \cdot 2 \mathrm{H}_{2} \mathrm{O}(3)$}

Different from compounds 1-2, selection of a flexible bis-pyridyl-bis-amide ligand 3-bpsa results in compound 3. X-ray diffraction analysis shows that the asymmetric unit of compound 3 consists of one independent $\mathrm{Cd}(\mathrm{II})$ ion, a half of 3-bpsa ligand, one 5AIP ligand, one coordinated water molecule and two lattice water molecules. The coordination environment of $\mathrm{Cd}(\mathrm{II})$ ion is shown in figure $3 \mathrm{a}$. The $\mathrm{Cd} 1$ ion is seven-coordinated by four carboxyl oxygen atoms from

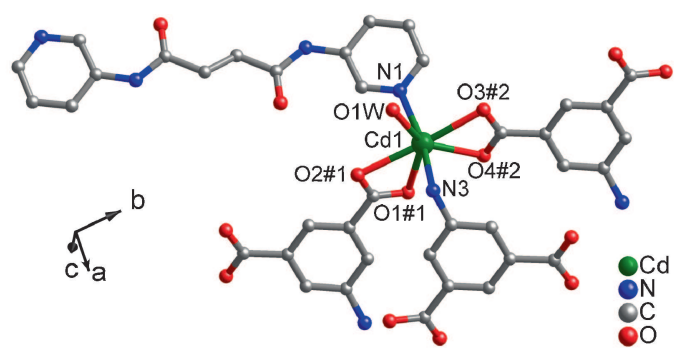

(a)

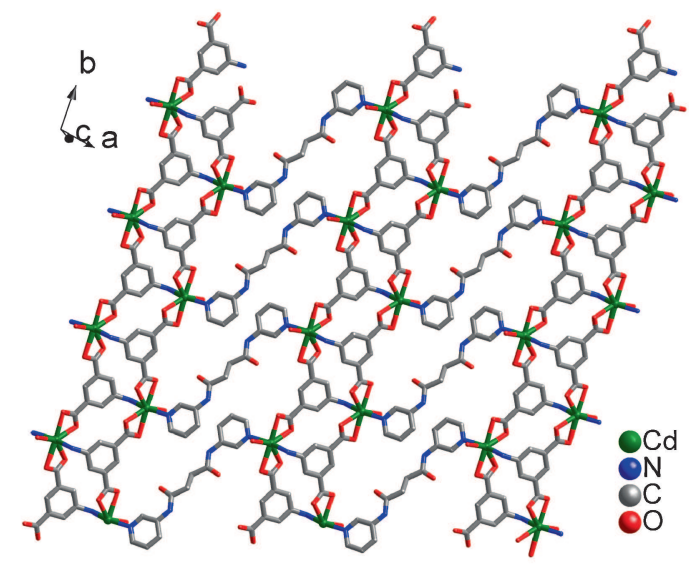

(b)

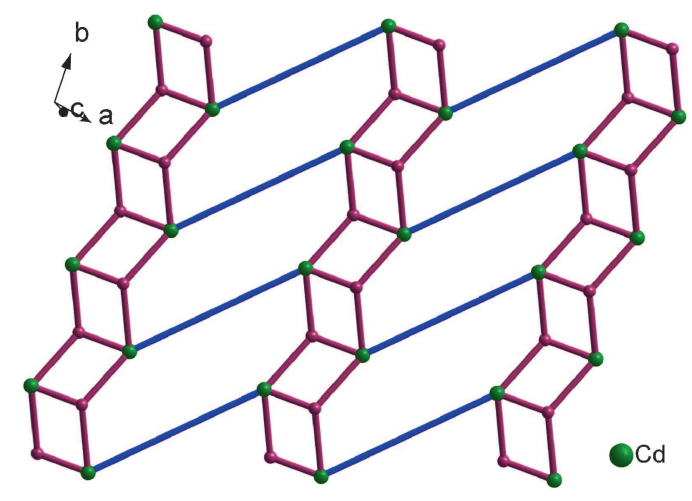

(c)

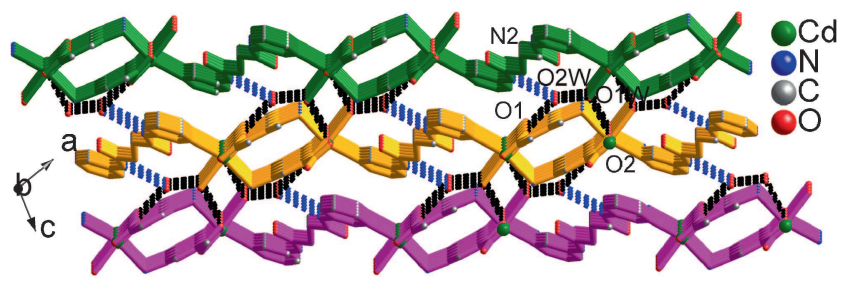

(d)

Figure 3. (a) The coordination environment for $\mathrm{Cd}(\mathrm{II})$ ion in compound 3 (at $50 \%$ probability level); (b) The 2 D polymer layer formed by $\left\{\mathrm{Cd}_{2}(5-\mathrm{AIP})_{2}\right\}_{\mathrm{n}}$ chains and 3-bpsa ligands; (c) The scheme of polymeric layer for 3; (d) The 3 D supramolecular framework of $\mathbf{3}$ formed by hydrogen bonding interactions [hydrogen bond: blue dot line, $\mathrm{N} 2 \cdots \mathrm{O} 2 \mathrm{~W}$; black dot line, $\mathrm{O} 1 \cdots \mathrm{O} 2 \mathrm{~W}, \mathrm{O} 1 \mathrm{~W} \cdots \mathrm{O} 2 \mathrm{~W}, \mathrm{O} 1 \mathrm{~W} \cdots \mathrm{O} 2]$. 
two 5-AIP ligands with $\mathrm{Cd}-\mathrm{O}$ distances of 2.310(4)2.503(4) $\AA$, one nitrogen atom from the amino group of 5-AIP [Cd1-N3 = 2.426(4) $\mathrm{A}]$, one nitrogen atom from a 3-bpsa ligand with Cd-N1 distance of 2.322(4) $\AA$, and one oxygen atom of a coordinated water molecule $[\mathrm{Cd}-$ $\mathrm{O} 1 \mathrm{~W}=2.321(4) \AA]$, showing a distorted decahedral geometry. In compound $\mathbf{3}$, the 5-AIP ligand adopts a monodentate-chelating-chelating coordination mode to bridge three $\mathrm{Cd}(\mathrm{II})$ ions with its two carboxyl groups and one amino group (table 2), which is different from that in compounds $\mathbf{1}$ and $\mathbf{2}$. For ligand 5-AIP in the three title compounds, the diversities of the coordination modes may be assigned to the different mixed ligands systems and different systematic $\mathrm{pH}$. Each 5-AIP bridging ligand links three adjacent $\mathrm{Cd}$ (II) ions to construct a $1 \mathrm{D}$ neutral $\left\{\mathrm{Cd}_{2}(5-\mathrm{AIP})_{2}\right\}_{\mathrm{n}}$ ribbon-like chain for 3 (figure S2) The 3-bpsa ligand displays a bidentate bridging coordination mode (via ligation of pyridyl nitrogen atoms), and its two pyridyl rings are parallel. The adjacent $1 \mathrm{D}\left\{\mathrm{Cd}_{2}(5-\mathrm{AIP})_{2}\right\}_{\mathrm{n}}$ ribbon-like chains are linked by the 3-bpsa to give a $2 \mathrm{D}$ polymeric layer of $\mathbf{3}$ (figure $3 b$ ).

Topologically, each $\mathrm{Cd}(\mathrm{II})$ ion is surrounded by one 3-bpsa ligand and three 5-AIP ligands, which can be defined as a 4-connected node. Each 5-AIP links three metal Cd(II) ions, regarded as a 3-connected node. The 3-bpsa ligating with two 4-connected Cd(II) ions serves as a simple linear linker. Thus the $2 \mathrm{D}$ layer of $\mathbf{3}$ is best described as a $(3,4)$-connected framework with $\left\{6^{2} .10\right\}\{6\}$ topology, as shown in figure $3 \mathrm{c}$. Moreover, the 2 D layers of $\mathbf{3}$ are extended into $3 \mathrm{D}$ supramolecular networks by two types of hydrogen bonding interactions $[\mathrm{N}-\mathrm{H} \cdots \mathrm{O}$ hydrogen bond: $\mathrm{N} 2 \cdots \mathrm{O} 2 \mathrm{~W}=$ 3.010(6) $\AA$; and O-H. . O hydrogen bond: O2W . . O 1 $=2.945(6), \mathrm{O} 2 \mathrm{~W} \cdots \mathrm{O} 1 \mathrm{~W}=2.768(6), \mathrm{O} 1 \mathrm{~W} \cdots \mathrm{O} 2=$ 2.697(5) $\AA$ ], as shown in figure $3 \mathrm{~d}$.

\subsection{Effect of semi-rigid/flexible bis-pyridyl-bis-amide ligands and 5-aminoisophthalate on the structures of three copper(II)/cadmium(II) coordination polymers}

In this paper, we chose two bis-pyridyl-bis-amide ligands: the semi-rigid 3-bpcb and the flexible 3-bpsa, to assemble with $\mathrm{Cu}(\mathrm{II}) / \mathrm{Cd}(\mathrm{II})$ ions and dicarboxylic acid (5- $\left.\mathrm{H}_{2} \mathrm{AIP}\right)$, aiming to study their influences on the architectures of the coordination polymers. As shown above, when semi-rigid 3-bpcb is selected as neutral $\mathrm{N}$-heterocyclic ligand to be introduced into the $\mathrm{Cu}-$ $5-\mathrm{H}_{2} \mathrm{AIP}$ or $\mathrm{Cd}-5-\mathrm{H}_{2} \mathrm{AIP}$ systems, two similar $2 \mathrm{D}$ double-layered architectures 1-2 are constructed. In these two compounds, the ligand 5-AIP adopts the same bridging coordination modes (monodentatemonodentate-chelating mode), which link the adjacent metal ions to form the similar $2 \mathrm{D}[\mathrm{M}(5-\mathrm{AIP})]_{\mathrm{n}}(\mathrm{M}=$ $\mathrm{Cu}(\mathrm{II})$ or $\mathrm{Cd}(\mathrm{II}))$ layers. Although 3-bpcb ligands display the same bidentate bridging modes, there are slight differences of conformations (table 2). For compounds 1-2, the similar $2 \mathrm{D}$ double-layered structures with $(3,4)$-connected $\left(6^{3}\right)\left(6^{5} \cdot 8\right)$ topologies are generated, but their final $3 \mathrm{D}$ supramolecular networks are slightly different due to the different coordination numbers of metal ions and organic ligand 3-bpcb.

For compounds $\mathbf{2}$ and $\mathbf{3}$, based on the same transitional metal $\mathrm{Cd}(\mathrm{II})$ ions and 5-AIP anions, when the flexible ligand 3-bpsa was used, the compound $\mathbf{3}$ with a $2 \mathrm{D}$ sheet structure was obtained. In compounds 2 and 3, the $\mathrm{Cd}$ (II) ions and 5-AIP ligands respectively exhibit different coordinated modes (table 2): $\mathrm{Cd}$ (II) ions, a six-coordinated distorted octahedral geometry (in 2) and a seven-coordinated distorted decahedral geometry (in 3); 5-AIP anions, a monodentate-monodentatechelating mode (in 2) and a monodentate-chelatingchelating mode (in $\mathbf{3}$ ). The $\mathrm{Cd}$ (II) ions are bridged by 5-AIP with different coordination modes to construct a $2 \mathrm{D}[\mathrm{Cd}(5-\mathrm{AIP})]_{\mathrm{n}}$ layer (for 2) or a $1 \mathrm{D}$ neutral $\left\{\mathrm{Cd}_{2}(5-\right.$ AIP $\left.)_{2}\right\}_{n}$ ribbon-like chain (for 3). Then ligands 3-bpcb or 3-bpsa showing $\mu_{2}$-bridging coordinated modes connect the adjacent $2 \mathrm{D}$ layers of $\mathbf{2}$ or $1 \mathrm{D}$ ribbon-like chains of $\mathbf{3}$. Consequently, the architecture of $\mathbf{3}$ is a $2 \mathrm{D}$ polymeric network with the $\left\{6^{2} .10\right\}\{6\}$ topology, which is completely different from that of $\mathbf{2}$. Notably, compounds 1-3 are 2 D layered polymers derived from transitional metal $\mathrm{Cu}(\mathrm{II}) / \mathrm{Cd}(\mathrm{II})$ ions bridged by the same dicarboxylate 5-AIP and ligands 3-bpcb or 3-bpsa, but they possess different structural features. Although many factors are involved, the differences of metal ions, bis-pyridyl-bis-amide ligands and their unique combination around metal ions, as depicted above, presumably play the key role in determining the final framework structures. These observations indicate the suitable combination of the semi-rigid/flexible bispyridyl-bis-amide ligands, dicarboxylates ligands and various transitional metal ions may lead to forming different architectures.

\subsection{Thermal stability analyses of compounds 1-3}

To study their thermal stabilities, thermal gravimetric (TG) analyses of compounds $\mathbf{1}-\mathbf{3}$ were performed under a flow of nitrogen with a heating rate of $10^{\circ} \mathrm{C} \mathrm{min}-1$ (figure 4). All of the TG curves exhibit two obvious weight loss steps in the region of $25-600^{\circ} \mathrm{C}$. For 1, the first weight loss indicates removal of the lattice water molecules (obsd.: $7.89 \%$, calcd.: $8.22 \%$ ) from $168^{\circ} \mathrm{C}$ to $225^{\circ} \mathrm{C}$. The second weight loss in the range of $290-500^{\circ} \mathrm{C}$ was assigned to the collapse of polymeric 


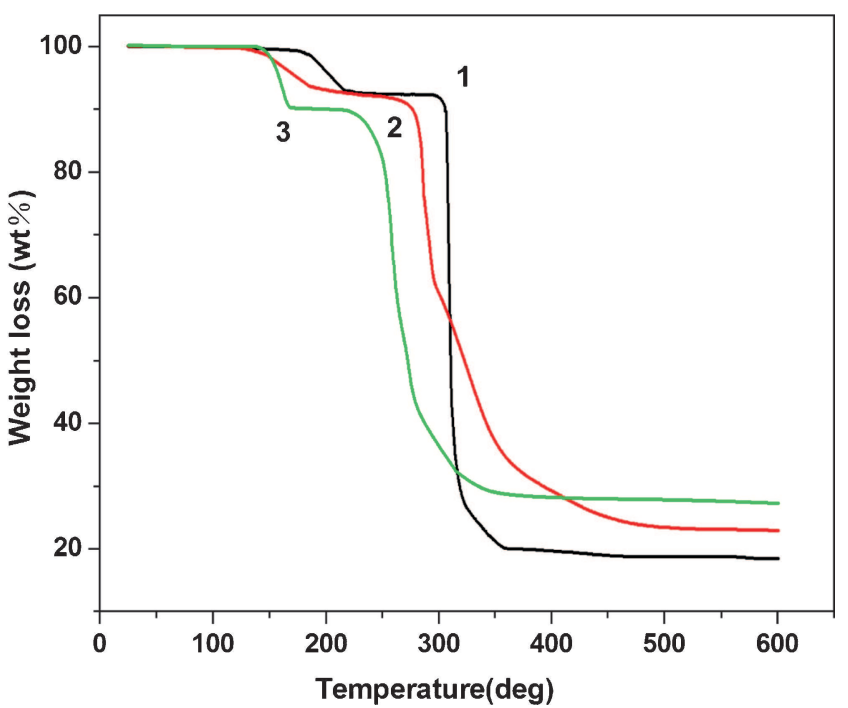

Figure 4. Thermal gravimetric curves of compounds 1-3.

framework. The remaining weight $(18.45 \%)$ corresponds to the percentage $(18.27 \%)$ of $\mathrm{Cu}$ and $\mathrm{O}$ components, indicating that the final product is $\mathrm{CuO}$. For compounds $\mathbf{2}$ and $\mathbf{3}$, the first weight loss of $7.75 \%$ in the range of $120-255^{\circ} \mathrm{C}$ for 2 and $10.83 \%$ in the range of $139-212^{\circ} \mathrm{C}$ for $\mathbf{3}$ are equivalent to the elimination of the coordinated water and lattice water molecules (calcd.: $7.40 \%$ for $\mathbf{2}, 11.23 \%$ for 3 ). The second weight loss was observed in the range of $260-450^{\circ} \mathrm{C}$ for 2 and $220-360^{\circ} \mathrm{C}$ for 3 , corresponding to the decomposition of organic ligands. The remaining residue corresponds to the formation of $\mathrm{CdO}$ (obsd.: $22.85 \%$, calcd.: $23.09 \%$ for 2; obsd.: $27.19 \%$, calcd.: $26.71 \%$ for 3 ).

\subsection{Electrochemical behavior of 1-CPE}

Recently, the redox properties of the copper(II) coordination compounds are found to be attractive for the application in electrochemical materials. ${ }^{24,39}$ The insolubility of the copper(II) compound $\mathbf{1}$ in water and common solvents illustrates that the bulk-modified carbon paste electrode (CPE) is the optimal selection for studying its electrochemical property. Compared with other modified film electrodes, the three-dimensional bulk-modified CPE shows high stability. This electrode can be renewed by squeezing a little carbon paste out glass tube and a fresh surface is exposed whenever needed, which is especially useful in practical applications The electrochemical behavior of $\mathbf{1}$ bulk-modified carbon paste electrode (1-CPE) was studied in $0.1 \mathrm{M}$ $\mathrm{H}_{2} \mathrm{SO}_{4}+0.05 \mathrm{M} \mathrm{Na}_{2} \mathrm{SO}_{4}$ aqueous solution. Figure 5 shows the cyclic voltammograms of the 1-CPE at different scan rates. It can be seen that there is a reversible redox peak at the 1-CPE in the potential range of 500

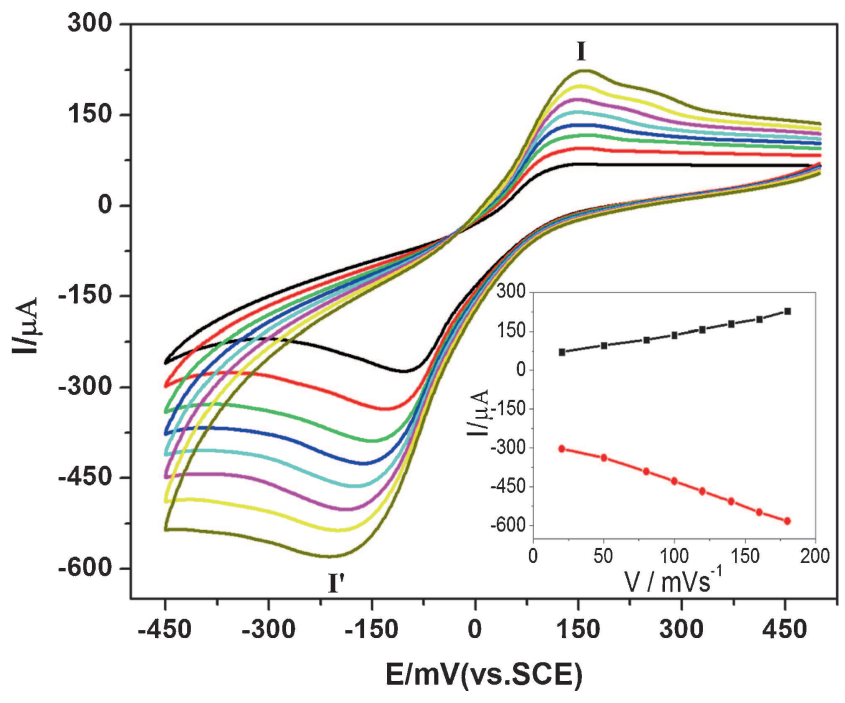

Figure 5. Cyclic voltammograms of 1-CPE in $0.1 \mathrm{M}$ $\mathrm{H}_{2} \mathrm{SO}_{4}+0.05 \mathrm{M} \mathrm{Na}_{2} \mathrm{SO}_{4}$ aqueous solution at different scan rates (from inner to outer) of 20, 50, 80, 100, 120, 140, 160, and $180 \mathrm{mVs}^{-1}$. The inset shows the plots of the anodic and the cathodic peak currents vs. scan rates.

to $-45 \mathrm{mV}$ and its mean peak potential $E_{1 / 2}=\left(E_{\mathrm{pa}}+\right.$ $\left.E_{\mathrm{pc}}\right) / 2$ was $-20 \mathrm{mV}$ (scan rate: $100 \mathrm{mV} \mathrm{s}^{-1}$ ), which should be attributed to the redox of $\mathrm{Cu}$ (II)/Cu(I). ${ }^{40,41}$ The effect of scan rates on the electrochemical behavior of the 1-CPE can be observed in figure 5. When the scan rates vary from 20 to $180 \mathrm{mVs}^{-1}$, the peak potentials change gradually: the cathodic peak potentials shifted to negative direction and the corresponding anodic peak potentials shifted to positive direction with increasing scan rate. As shown in inset of figure 5 the anodic and the cathodic peak currents were proportional to the scan rates, indicating that the redox process for 1-CPE was a surface-controlled process The electrochemical behavior of 1-CPE is similar to those of other $\mathrm{Cu}(\mathrm{II})$ compounds bulk-modified CPEs. ${ }^{42,43}$ The differences of peak potential for these $\mathrm{Cu}$ (II) compounds based-CPEs may be attributed to the different coordination environments of copper(II) ions, various organic ligands and diverse coordination frameworks of copper compounds. $^{24}$

\subsection{Fluorescent properties of compounds $\mathbf{1 - 3}$}

In order to study the fluorescent properties and potential applications of the title complexes, we have measured the emission spectra of compounds $\mathbf{1}-\mathbf{3}$ and the free ligands 3-bpcb and 3-bpsa in the solid state at room temperature. As shown in the insert of figure 6 , the free 3-bpcb and 3-bpsa ligands display emission at $446 \mathrm{~nm}$ and $400 \mathrm{~nm}\left(\lambda_{\mathrm{ex}}=300 \mathrm{~nm}\right)$, respectively, which may be attributed to the $\pi-\pi *$ transitions. $^{44,45}$ For compounds 


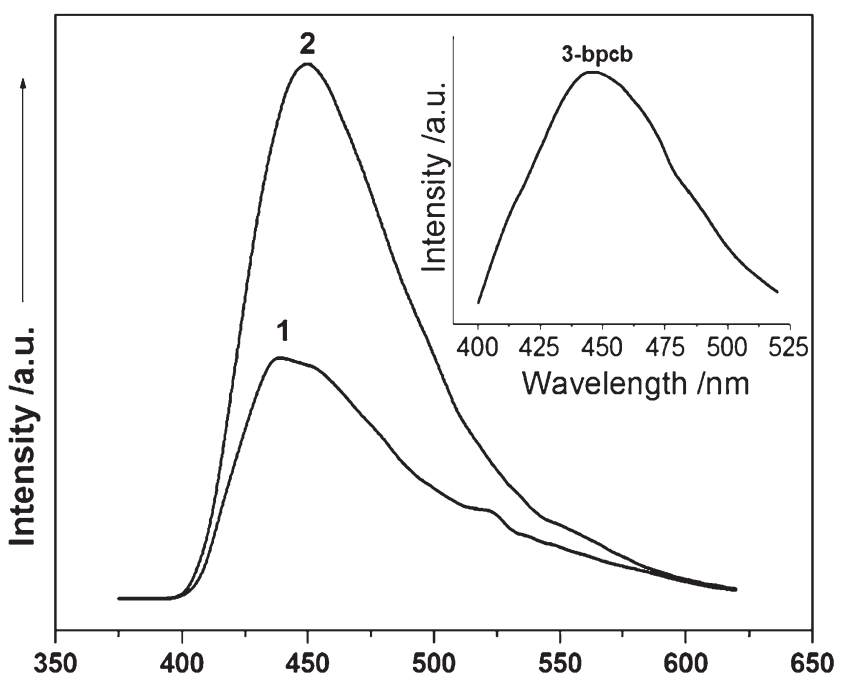

(a)

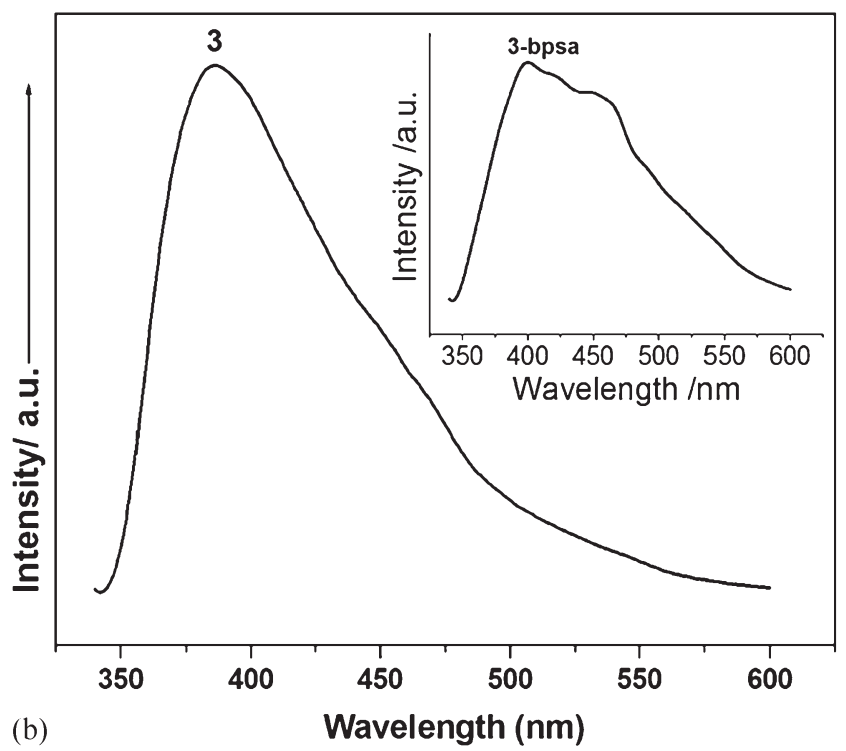

Figure 6. (a) The fluorescent emission spectra of compounds 1-2 (The inset shows the fluorescent spectra of the free ligand 3-bpcb); (b) The fluorescent emission spectrum of compound $\mathbf{3}$ (The inset is the fluorescent emission of the free ligand 3-bpsa).

$\mathbf{1}$ and $\mathbf{2}$, the intense fluorescent emissions are observed at $439 \mathrm{~nm}$ for $\mathbf{1}$ and $449 \mathrm{~nm}$ for 2 (figure 6a), respectively. Compared with the 3-bpcb, compound $\mathbf{1}$ is blueshifted with $7 \mathrm{~nm}$, while the compound $\mathbf{2}$ is red shifted by $3 \mathrm{~nm}$. For $\mathbf{3}$, the emission peak can be seen at $386 \mathrm{~nm}$ (figure 6b). Compared to the free ligand 3-bpsa, compound $\mathbf{3}$ is blue-shifted by $14 \mathrm{~nm}$. The blue-shift (for $\mathbf{1}$ and 3) or red-shift (for 2) phenomena in the emission spectra may be attributed to ligand-centered electronic transition or metal-to-ligand charge transfer transition, which is similar to the reported $\mathrm{d}^{10}$ metal complexes
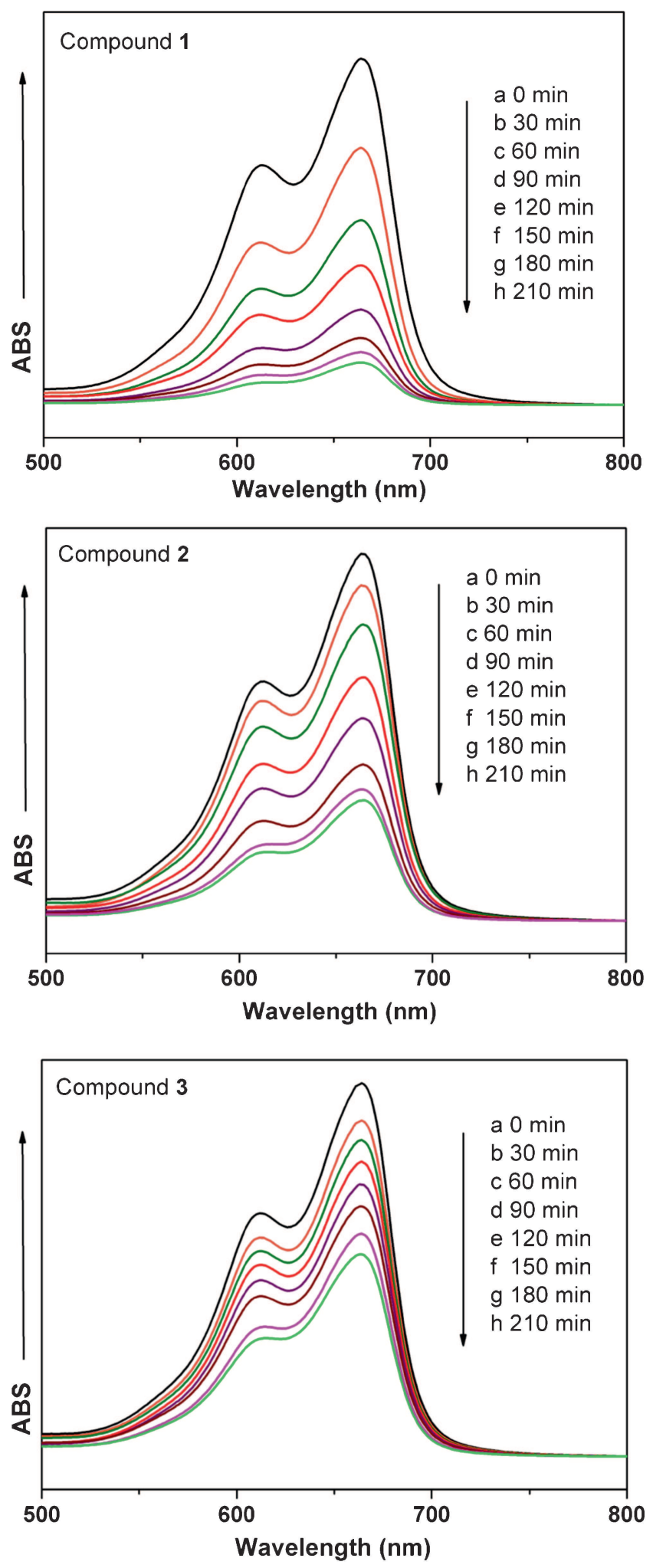

Figure 7. Absorption spectra of the MB solution during the decomposition reaction under UV irradiation with the presence of compounds $\mathbf{1}-\mathbf{3}$.

with N-donor ligands. ${ }^{46-48}$ The differences in fluorescence behaviors for compounds $\mathbf{1}-\mathbf{3}$ are probably caused by the various $\mathrm{N}$-donor ligands, different metal ions 
and their coordination environments as well as the final coordination frameworks.

\subsection{Photocatalytic properties of compounds 1-3}

Recently, coordination polymers as photocatalysts have attracted much attention due to their potential applications in purifying waste streams under UV irradiation by decomposing organic dyes. ${ }^{49-51}$ In this work, methylene blue (MB) is selected as a model pollutant in aqueous media to evaluate the photocatalytic effectiveness of the compounds 1-3. The photodecomposition experiments of MB have been investigated through a typical process: $60 \mathrm{mg}$ powder of compounds $\mathbf{1}-\mathbf{3}$ was mixed with $90 \mathrm{~mL} \mathrm{MB}$ aqueous solution $\left(10.0 \mathrm{mg} \mathrm{L}^{-1}\right)$, and stirred for $30 \mathrm{~min}$ in the dark. Then the solution was exposed to UV irradiation and kept stirring. Each sample $(5.0 \mathrm{~mL})$ was taken out for analysis every $30 \mathrm{~min}$. It can be found that the absorption peaks of MB decrease gradually as time goes by (figure 7). Additionally, the concentration of MB solution vs reaction time $(t)$ of compounds 1-3 was plotted. As depicted in figure S3, it can be observed that the photocatalytic activities increased from $9 \%$ (without any catalyst) to about $87 \%$ for $\mathbf{1}, 67 \%$ for $\mathbf{2}$ and $45 \%$ for $\mathbf{3}$ after UV irradiation for a duration of $210 \mathrm{~min}$. These experimental results indicate that compounds $\mathbf{1}-\mathbf{3}$ possess good photocatalytic activities for the degradation of $\mathrm{MB}$ under UV irradiation, which may be used as potential candidates as photocatalysts for the reduction of some organic dyes.

\section{Conclusions}

In summary, three new metalorganic coordination compounds derived from the semi-rigid/flexible bis-pyridylbis-amide ligands (3-bpcb and 3-bpsa) and the aromatic dicarboxylate 5- $\mathrm{H}_{2}$ AIP have been hydrothermally synthesized. Three compounds show diverse layer structures with two kinds of topologies: $\left(6^{3}\right)\left(6^{5} \cdot 8\right)$ topology for $\mathbf{1}$ and $\mathbf{2},\left\{6^{2} .10\{6\}\right.$ topology for $\mathbf{3}$. The bis-pyridyl-bis-amide ligands with different flexibility show great effect on the structures of title compounds. Moreover, the electrochemical behavior of compound $\mathbf{1}$ and fluorescent properties of the title compounds may make them potential candidates as electrochemical and fluorescent materials. Further studies on synthesis of other metal-organic complexes with this semi-rigid/flexible bis-pyridyl-bisamide ligand and its analogues are underway in our laboratory.

\section{Supplementary Information}

Crystallographic data for the structures reported in the paper have been deposited in the Cambridge Crystallographic Data Center with CCDC reference numbers CCDC 949958 for 1, 949959 for $\mathbf{2}$ and 1024049 for 3. These data can be obtained free of charge from The Cambridge Crystallographic Data Centre via www. ccdc.cam.ac.uk/data_request/cif. The tables of selected bond lengths and angles, the related hydrogen bonding geometries of compounds $\mathbf{1}-\mathbf{3}$, as well as additional figures are available at www.ias.ac.in/chemsci.

\section{Acknowledgements}

The supports of the National Natural Science Foundation of China (No. 21471021), New Century Excellent Talents in University (NCET-09-0853), and Program of Innovative Research Team in University of Liaoning Province (LT2012020) are gratefully acknowledged.

\section{References}

1. Han M L, Wang J G, Ma L F, Guo H and Wang L Y 2012 Cryst. Eng. Comm. 142691

2. Pramanik S, Zheng C, Zhang X, Emge T J and Li J 2011 J. Am. Chem. Soc. 1334153

3. Chu W J, Yao H C, Fan Y T and Hou H W 2011 Dalton Trans. 402555

4. Lucas J S, Pochodylo A L and LaDuca R L 2010 Cryst. Eng. Comm. 123310

5. Ren C, Hou L, Liu B, Yang G P, Wang Y Y and Shi Q Z 2011 Dalton Trans. 40793

6. Su Z, Xu J, Fan J, Liu D J, Chu Q, Chen M S, Chen S S, Liu G X, Wang X F and Sun W Y 2009 Cryst. Growth Des. 92801

7. Lama P, Aijaz A, Sañudo E C and Bharadwaj P K 2010 Cryst. Growth Des. 10283

8. Chang Z, Zhang A S, Hu T L and Bu X H 2009 Cryst. Growth Des. 94840

9. Chen W X, Wu S T, Long L S, Huang R B and Zheng L S 2007 Cryst. Growth Des. 71171

10. He K H, Li Y W, Chen Y Q, Song W C and Bu X H 2012 Cryst. Growth Des 122730

11. Sposato L K, Nettleman J A and LaDuca R L 2010 Cryst. Eng. Comm. 122374

12. Gandolfo C M and LaDuca R L 2011 Cryst. Growth Des. 111328

13. Rajadurai C, Enkelmann V, Ikorskii V, Ovcharenko V I and Baumgarten M 2006 Inorg. Chem. 69664

14. Wang X L, Lin H Y, Mu B, Tian A X and Liu G C 2010 Dalton Trans. 396187

15. Wang X L, Mu B, Lin H Y and Liu G C $2011 \mathrm{~J}$. Organomet. Chem. 6962313

16. Adarsh N N, Greilard A, Dufourc E J and Dastidar P 2012 Cryst. Growth Des. 123369

17. Sun G M, Huang H X, Tian X Z, Song Y M, Zhu Y, Yuan Z J, Xu W Y, Luo M B, Liu S J, Feng X F and Luo F 2012 Cryst. Eng. Comm. 146182 
18. C Wang Y, Wilseck Z M, Supkowski R M and LaDuca R L 2011 Cryst. Eng. Comm. 131391

19. Gong Y, Li J, Qin J B, Wu T, Cao R and Li J H 2011 Cryst. Growth Des. 111662

20. Cheng J J, Chang Y T, Wu C J, Hsu Y F, Lin C, Proserpio D and Chen J D 2012 Cryst. Eng. Comm. 14537

21. Hu H L, Hsu Y F, Wu C J, Yeh C W, Chen J D and Wang J C 2012 Polyhedron 33280

22. Wang X L, Sui F F, Lin H Y, Xu C, Liu G C, Zhang J W and Tian A X 2013 Cryst. Eng. Comm. 157274

23. Wang X L, Luan J, Sui F F, Lin H Y, Liu G C and Xu C 2013 Cryst. Growth Des. 133561

24. Wang X L, Luan J, Lin H Y, Lu Q L, Xu C and Liu G C 2013 Dalton Trans. 428375

25. Wang X L, Mu B, Lin H Y, Yang S, Liu G C, Tian A X and Zhang J W 2012 Dalton Trans. 4111074

26. Sarkar M and Biradha K 2006 Cryst. Growth Des. 6202

27. Muthu S, Yip J H K and Vittal J J 2002 J. Chem. Soc., Dalton Trans. 4561

28. Sheldrick G M 1997 SHELXS-97: Program for Crystal Structure Solution (Göttingen, Germany: Göttingen University)

29. Sheldrick G M 1997 SHELXS-97: Program for Crystal Structure Refinement (Göttingen, Germany: Göttingen University)

30. Chang X H, Qin J H, Han M L, Ma L F and Wang L Y 2014 Cryst. Eng. Comm. 16870

31. Luo L, Lv G C, Wang P, Liu Q, Chen K and Sun W Y 2013 Cryst. Eng. Comm. 159537

32. Mitkina T V, Zakharchuk N F, Naumov D Y, Gerasko O A, Fenske D and Fedin V P 2008 Inorg. Chem. 476748

33. Song X Z, Song S Y, Qin C, Su S Q, Zhao S N, Zhu M, Hao Z M and Zhang H J 2012 Cryst. Growth Des. 12 253

34. Wang H N, Meng X, Qin C, Wang X L, Yang G S and Su Z M 2012 Dalton Trans. 411047
35. Zeng M H, Zou H H, Hu S, Zhou Y L, Du M and Sun H L 2009 Cryst. Growth Des. 94239

36. Lin H Y, Liu P, Zhang J W, Wang X L and Liu G C 2013 J. Coord. Chem. 66612

37. Wang X L, Mu B, Lin H Y, Yang S and Liu G C 2013 J. Mol. Struct. 1036380

38. Wang X L, Mu B, Lin H Y, Yang S, Liu G C, Tian A X and Zhang J W 2013 Sci. China Chem. 56557

39. Hazra S, Majumder S, Fleck M, Aliaga-Alcalde N and Mohanta S 2009 Polyhedron 283707

40. Lin H Y, Liu P, Wang X L, Xu C and Liu G C 2013 Z. Naturforsch. 68b 138

41. Wang X L, Zhao H Y, Lin H Y, Liu G C, Fang J N and Chen B K 2008 Electroanalysis 201055

42. Lin H Y, Wang X L, Hu H L, Chen B K and Liu G C 2009 Solid State Sci. 11643

43. Wang X L, Lin H Y, Mu B, Tian A X, Liu G C and Hu N H 2011 Cryst. Eng. Comm. 131990

44. Chen S S, Zhao Y, Fan J, Okamura T, Bai Z S, Chen Z H and Sun W Y 2012 Cryst. Eng. Comm. 14 3564

45. Xu C Y, Li L K, Wang Y P, Guo Q Q, Wang X J, Hou H W and Fan Y T 2011 Cryst. Growth Des. 114667

46. Cui Y J, Yue Y F, Qian G D and Chen B L 2012 Chem. Rev. 1121126

47. Gong Y, Wu T, Lin J H and Wang B S 2012 Cryst. Eng. Comm. 145649

48. Zhang L, Zhao J L, Lin Q P, Qin Y Y, Zhang J, Yin P X, Cheng J K and Yao Y G 2009 Inorg. Chem. 48 6517

49. Liu B, Yu Z T, Yang J, Wu H, Liu Y Y and Ma J F 2011 Inorg. Chem. $\mathbf{5 0} 8967$

50. Chen Y Q, Li G R, Qu Y K, Zhang Y H, He K H, Gao Q and Bu X H 2013 Cryst. Growth Des. 13901

51. Sun C Y, Wang X L, Qin C, Jin J L, Su Z M, Huang P and Shao K Z 2013 Chem. Eur. J. 113639 